\title{
A case-control study of microenvironmental risk factors for urban visceral leishmaniasis in a large city in Brazil, 1999-2000
}

\author{
Claudia Di Lorenzo Oliveira, ${ }^{1}$ Ana Diez-Roux, ${ }^{2}$ Cibele Comini César, ${ }^{3}$ \\ and Fernando Augusto Proietti ${ }^{4}$
}

Suggested citation Oliveira CDL, Diez-Roux A, César CC, Proietti FA. A case-control study of microenvironmental risk factors for urban visceral leishmaniasis in a large city in Brazil, 1999-2000. Rev Panam Salud Publica. 2006;20(6):369-76.

ABSTRACT Objectives. We investigated potential microenvironmental risk factors for visceral leishmaniasis in urban and suburban areas, and developed risk scores to characterize the household and the neighborhood. These scores may be useful to identify microenvironments within cities that place residents at greater risk of visceral leishmaniasis.

Methods. In this case-control study, cases were all persons with visceral leishmaniasis reported from July 1999 through December 2000 in the Belo Horizonte metropolitan area, Brazil. Two kinds of controls - neighborhood and hospital-were used. Cases and controls were matched by age ( \pm 2 years). We developed four scores to characterize the microenvironment (indoor, outdoor, animal indoor, and animal outdoor), and also considered the level of urbanization of the area.

Results. A total of 106 neighborhood controls and 60 hospital controls were identified for 109 cases. Among the cases, 69 (63.3\%) were men and 40 (36.7\%) were women. Most cases were under 15 years old $(64.2 \%)$, and $39(35.8 \%)$ were 15 years old or more. The outdoor score [odds ratio $(O R)=1.49 ; 95 \%$ confidence interval $(C I)=1.03-2.14$ ] and animal outdoor scores $(O R=1.79[95 \%$ CI 1.21-2.65]) were significantly associated with the odds of visceral leishmaniasis in our sample. We also found a significant interaction between sex and age. Compared to females 15 years old or more, males 15 years old or more were more likely to have visceral leishmaniasis (OR $=7.02[95 \%$ CI 2.20-22.20]).

Conclusions. Animals in the neighborhood were associated with a greater odds of visceral leishmaniasis. Cases were more likely than controls to live in transitional or rural areas, although this difference was not statistically significant, possibly because of the small sample size.

Key words Case-control studies; leishmaniasis, visceral; risk factors; urbanization; Brazil.

Hospital das Clínicas, Universidade Federal de Minas Gerais, Belo Horizonte, MG, Brazil. Send correspondence and reprint requests to: Claudia Di Lorenzo Oliveira, Ave Alfredo Balena, 190, Faculdade de Medicina, sala 9007, Bairro Santa Efigênio, Belo Horizonte, MG, Brazil 30130-100; e-mail: dlorenzo@medicina.ufmg.br

2 Center for Social Epidemiology and Population Health, University of Michigan, Ann Arbor, Michigan, United States of America.
Urbanization, climate change and variability, trade and human move-

\footnotetext{
Departamento de Estatística, Instituto de Ciências Exatas, Universidade Federal de Minas Gerais, Belo Horizonte, MG, Brazil.

4 Departamento de Medicina Preventiva e Social, Faculdade de Medicina, Universidade Federal de Minas Gerais, Belo Horizonte, MG, Brazil.
}

ments, pollution, land use, water storage, and irrigation are aspects of global change that are likely to influence the vector-borne disease incidence rate and the worldwide distribution of diseases transmitted by vectors. Although the extent of these changes is difficult to predict, it is esti- 
mated that in 2030, 5 billion people will be living in urban areas worldwide (1), and this intensification of urban population growth is likely to increase outbreaks of vector-borne diseases in urban areas (2).

Although visceral leishmaniasis (VL) is an ancient disease, the measures adopted by health systems to control it have not been successful, and the problem has been worsening. In the Belo Horizonte metropolitan area (state of Minas Gerais, Brazil), the first autochthonous human case by vector transmission was reported in 1989 (3), in the city of Sabará. In 1992, seropositive dogs were detected in the capital, Belo Horizonte, and the first human case in the capital city occurred in 1994. Since then the number of cases has been increasing, mainly among children and older adults. Between 1996 and 2001 the prevalence of VL increased from 7.09 per 100000 to 8.30 per 100000 among children under 5 years of age, and from 0 to 1.37 per 100000 in adults aged 55 and older (4).

An important ecological characteristic of the disease in urban areas is spatial clustering associated with the presence of dogs (5). However, the association of leishmaniasis with the presence of dogs in the household has not been confirmed at the individual level (6). Conflicting reports led some to question the importance of dogs in the epidemiology of VL, and of the efficiency of the elimination of dogs as a disease control strategy. Other reservoirs, such as marsupials, may be responsible for maintaining the disease in areas where controls of domestic reservoirs such as dogs have been implemented $(7,8)$.

Although many studies of the ecology of the vector have been performed (9-13), it is still difficult for local public health services to decide which areas should receive high priority for insecticide treatment. An indicator of the density of the vector is difficult to obtain for large urban areas because of the logistic complexities of data collection, which is very labor-intensive and requires a large number of traps $(13,14)$. In addition, because of the length of time between the onset of infection and the development of the disease, it is difficult to find a statistical correlation between vector density and the leishmaniasis incidence rate. The identification of alternative indicators of leishmaniasis risk would be useful to public health efforts to prevent the disease.

Using a case-control design similar to that of an earlier study by Costa et al. (15), we investigated a set of potential microenvironmental risk factors for leishmaniasis in urban and suburban areas. As microenvironmental factors we considered the characteristics of the neighborhood and the house, such as the level of urbanization, the quality of the dwelling, and the presence of free-roaming animals. Our hypothesis was that better urbanization conditions protect against the occurrence of leishmaniasis. We developed risk scores to characterize households and neighborhoods, which may be useful to identify microenvironments within cities that place residents at greater risk of leishmaniasis.

\section{MATERIAL AND METHODS}

\section{Study sample and data collection}

A case-control study was conducted. Cases were all persons with VL notified to the local epidemiological service from July 1999 through December 2000 in the Belo Horizonte metropolitan area. This is the third largest metropolitan area in Brazil, with 4357942 inhabitants and 33 cities. When a case is diagnosed by the medical service, it must be reported to the Metropolitan Health Service, which controls the distribution of meglumine antimoniate (Glucantime) for treatment. Cases were identified from this register and confirmed by clinical and parasitological examination. We also reviewed the hospitalization form processed by the Brazilian National Inpatient Information System (SIH-SUS) in order to detect any cases that had been missed.

Two kinds of controls were selected: neighborhood controls and hospital controls. Neighborhood controls were selected according to a specified pro- cedure among neighbors of the cases, matched for age within 2 years. After a case participant was interviewed, one of the three interviewers visited a randomly selected immediate neighbor living in the dwelling to the right or left of the case. Residents in the house were counted and their ages recorded. If one of the residents was eligible to participate as a control based on the age of the case, he or she was invited to participate. If more than one resident was eligible, the interviewer chose the person whose birth date most closely matched that of the case. If the person selected was under 18 years of age, consent was obtained from a responsible adult. If no eligible participants were identified in the first house visited, the interviewer visited the next house in the same direction (left or right) until an eligible control was identified.

For neighborhood controls we collected blood samples on filter paper (Whatman 3) and processed it to detect anti-Leishmania-specific antibodies by indirect immunofluorescent assay (IFI) (in-house assay, L. amazonensis MHOM/BR/60/BH6) and the enzyme-linked immunosorbent assay (ELISA) (in-house assay, L. amazonensis $\mathrm{MHOM} / \mathrm{BR} / 60 / \mathrm{BH} 6)$. Persons were excluded as controls when both results were positive (1:40 for IFI, and absorbance $>0.1$ for ELISA).

Hospital controls were selected from a list of inpatients who had received treatment in the same hospital as the case, matched by age within 2 years, and day of admission within 15 days. A list of inpatients ordered by admission date was created by the local Public Health Service for each hospital. We chose the inpatient whose age most closely matched the case's age within 2 years and admitted closest to the admission date of the case but not more than 15 days before or after the case was admitted. After hospital control participants were identified, their medical records were reviewed to determine eligibility. If the inpatient was eligible to participate we visited her or him at home. Inpatients with a diagnosis of any type of leishmaniasis were excluded. We also ex- 
cluded inpatients with a diagnosis of infectious disease that could be misdiagnosed as leishmaniasis (schistosomiasis or mononucleosis) and patients with asthma, AIDS, or tuberculosis, because these patients were unlikely to be representative of noncases of leishmaniasis in the population. Patients with psychiatric disorders were excluded due to difficulties with the interview, and patients without a diagnosis were also excluded.

Cases and controls responded to an interviewer-administered questionnaire on their socioeconomic position, personal habits, and microenvironmental characteristics of their homes. After completing the interview, the interviewer walked around the block and completed a questionnaire with information on microenvironmental characteristics and the level of urbanization of the neighborhood. In this paper we refer to this questionnaire as the "block questionnaire." Before the field work was started, a pilot study was conducted that included standardization of interviewer responses to the block questionnaire.

The final sample included 109 cases, 106 neighborhood controls (matched to 106 cases, 1 case: 1 control), and 60 hospital controls (matched to 60 cases; 1 case: 1 control). Cases without a control were excluded from the analyses (see the Statistical analysis section below). This study was approved by the Ethical Committee of Minas Gerais Federal University and by the committees of the participating hospitals. All participants signed a written informed consent form.

\section{Statistical analysis}

Univariate analysis was performed, followed by conditional logistic regression. We used chi-square tests to compare dichotomous variables, and $t$ tests to compare means for continuous variables. We also calculated the odds ratio with 95\% confidence intervals for each variable. Variables with an associated $P$ value $\leq 0.25$ were included in the logistic regression models. Stata v. 8.1 software (StataCorp LP, College
Station, Texas, United States) was used for all analyses.

Independent variables were classified into five groups: socioeconomic characteristics, indoor characteristics of the home (indoor score), outdoor characteristics of the home (outdoor score), animals inside the house (animal indoor score), animals in the neighborhood (animal outdoor score), and level of urbanization in the area. All scores were constructed so that an increasing score was hypothesized to be associated with increasing risk of leishmaniasis. The methodology used to create the scores is described below.

The variables used to construct the indoor score included: the type of roof, type of floor, ratio of inhabitants to number of rooms, type of water supply, type of bathroom, type of sewer, disposal of water used in the kitchen, and whether the house was remodeled. Variables for the outdoor score included the presence of a yard and type of yard; the presence of a marsh, rubbish, or natural springs; the presence of vegetable plots, trees, banana plants, or other natural vegetation; the presence of worms in the garden, the presence of stored water, the type of garbage disposal, and the frequency with which the yard was cleaned. Table 1 summarizes the variables used in each of the scores.

The animal indoor score quantified the presence of animals in the house. It was a dichotomous variable: no animals in house was scored as 0 , and the presence of at least one animal in house, including dogs, cats, chickens, pigs, horses, cows, geese, ducks, and other birds, was scored as 1 . The animal outdoor score quantified the frequency with which the respondent has seen the animals listed above, plus marsupials, rats, and snakes, in the neighborhood.

We also created a classification for neighborhood areas based on their level of urbanization, using information from the block questionnaire. Areas were classified into three groups: urbanized areas in good condition, urbanized areas in poor condition, and transitional or rural areas. Urbanized areas in good condition included only residential areas and were characterized by paving of all streets with asphalt or cobblestones, no homeless persons or animals in the street, and the presence of street lights and sidewalks. Urbanized areas in poor condition included residential or commercial areas without woods nearby, a mix of paved and unpaved streets, and sidewalks absent or present only in part of the block. Most blocks in poorly urbanized areas had street lights, but animals were common in the streets. The third category included residential areas near wooded areas or areas classified as rural by the interviewer. Most had street lights, but no sidewalks or paving. Animals were present in most of the streets. Some slums were classified as urbanized areas in poor condition, and others were classified as transitional areas.

Because of the matched design, conditional logistic regression was used in all analyses. Three sets of regressions were run: the full sample, including all cases and controls (matched for age); cases and hospital controls (matched for age and hospital); and cases and neighborhood controls (matched for age and neighborhood). Independent variables were included in the models as follows: sex (dichotomous), age (below 15 years vs. 15 years or more), indoor score (continuous), outdoor score (continuous), animal indoor score (dichotomous), animal outdoor score (continuous), and urbanization category (2 dummy variables). To provide a useful interpretation for continuous scale covariates, we transformed the scores into standardized scores (16). The odds ratio (OR) associated with each variable thus represented the change in the odds associated with one unit of standard deviation of the variable, adjusted for all other variables in the model. For example, the odds ratio of visceral leishmaniasis increased by 1.29 when the standard deviation of the indoor score increased by 1.95 units.

We tested two interactions: between sex and age, because such interaction has been previously reported (17), and between outdoor score and level of urbanization, because we hypothesized that the effect of the outdoor score 
TABLE 1. Variables used in the construction of the indoor score, outdoor score, and animal outdoor score and points assigned to each level, metropolitan area of Belo Horizonte, Brazil, July 1999 to December 2000

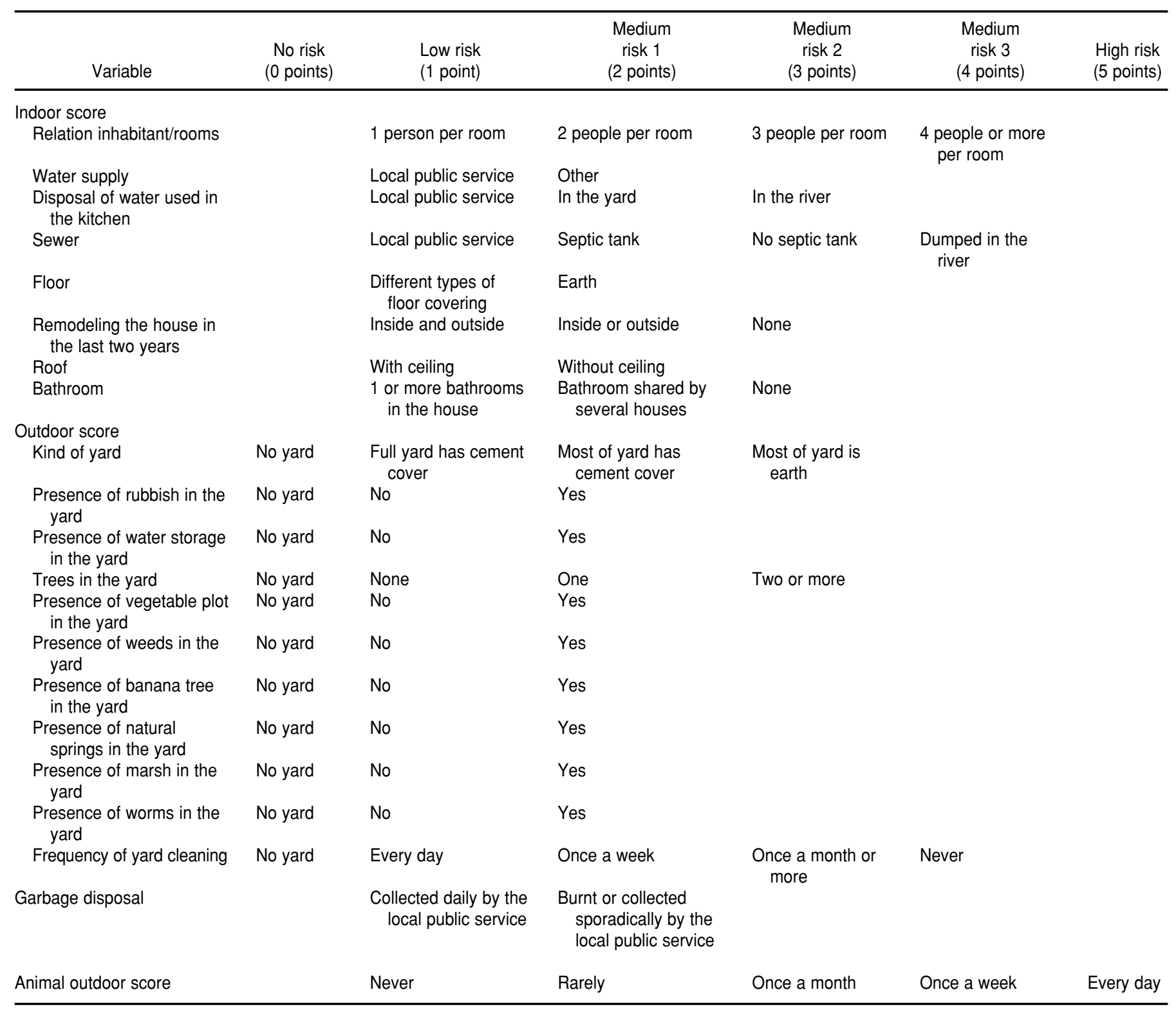

would vary based on broader characteristics of the neighborhood environment.

Models were constructed in steps. We began with a full model, with all the variables and the two interaction terms described above. We fitted the same model combining both control groups, and for each control group separately. Interactions between the outdoor score and the level of urbanization were eliminated because they were not statistically significant $(P>$ $0.05)$. Sex $\times$ age interactions were re- tained because they were statistically significant in all models $(P<0.05)$. The presence of animals in the house was also eliminated because it was not statistically significant in the bivariate analysis or in any of the models $(P>$ $0.10)$ that we fitted with both control groups together and each control group separately. Urbanization categories were not interpretable when cases and controls were matched for neighborhoods. However, they were retained in the models for purposes of comparison because their effects were in the expected direction for analyses of hospital controls (although the ORs were not statistically significant due to limited sample size.)

\section{RESULTS}

During the period of study 148 cases were notified. We could not verify the address of $18(12.2 \%)$ cases, 1 was homeless $(0.7 \%), 15$ had died $(10 \%), 2$ 
refused to participate $(1.4 \%)$, and 3 $(2.0 \%)$ were excluded because their neighborhood control participant was positive for both serologic tests), leaving a total of 109 cases $(73.6 \%$ of all notified cases) available for analysis. Neighborhood- and age-matched controls were identified for 106 of the 109 cases. Hospital- and age-matched controls were identified for 60 of the 109 cases. The smaller number of hospital controls is due to the fact that at four hospitals we were not able to access the list of inpatients. In addition, one of the hospitals was specialized in infectious disease so we were not able to identify eligible controls, and two of the patients had not been hospitalized.

Selected characteristics of cases and controls are shown in Table 2. Among the cases, $69(63.3 \%)$ were men and 40 $(36.7 \%)$ were women. Most cases were under 15 years old $(64.2 \%)$, and only 5 cases were over 45 years old. Most cases had a monthly family income under US\$ 226.50 (85.3\%). Most cases lived in a house or apartment $(65.1 \%)$, and the rest $(34.9 \%)$ lived in singleroom houses or the types of accommodations typical of Brazilian slums. In terms of the kind of urbanization, 30.2\% of the cases lived in urbanized areas in good condition, $35.8 \%$ lived in urbanized areas in poor condition, and 34.0\% lived in transitional or rural areas. Most cases $(72.5 \%)$ had animals in the house.

Hospital and neighborhood controls did not differ significantly in most of the variables of interest. The distribution by age group, income, schooling, and type of dwelling was similar in both types of controls. They differed in marital status, but this variable was not related to leishmaniasis. They also differed in level of urbanization, but this was to be expected given that neighborhood controls were matched to cases according to neighborhood of residence. The two types of controls did not differ significantly in indoor, outdoor, or animal outdoor scores $(P>$ 0.05) (Table 3).

Cases and controls did not differ significantly in marital status, income, schooling, kind of house, or the presence of animals in the house $(P>0.05)$. Cases were significantly more likely to be male $(\mathrm{OR}=2.30)$ (Table 2), and were also more likely to live in single-room houses $(\mathrm{OR}=2.12)$. Mean indoor, out-

TABLE 2. Univariate analysis of characteristics associated with leishmaniasis in cases and controls, metropolitan area of Belo Horizonte, Brazil, July 1999 to December 2000

\begin{tabular}{|c|c|c|c|c|c|c|}
\hline & $\begin{array}{l}\text { Hospital } \\
\text { controls } \\
(\text { No. = 60) } \\
\end{array}$ & $\begin{array}{c}\text { Neighborhood } \\
\text { controls } \\
(\text { No. }=106) \\
\end{array}$ & & $\begin{array}{c}\text { All } \\
\text { controls } \\
(\text { No. }=166) \\
\end{array}$ & $\begin{array}{c}\text { Cases } \\
(\text { No. }=109) \\
\end{array}$ & Odds ratio (OR) \\
\hline Variable & $\mathrm{N}(\%)$ & $\mathrm{N}(\%)$ & $P$ value $^{\mathrm{a}}$ & $\mathrm{N}(\%)$ & $\mathrm{N}(\%)$ & OR $(95 \% \mathrm{Cl})$ \\
\hline \multicolumn{7}{|l|}{ Sex } \\
\hline Female & $32(53.3)$ & $63(59.4)$ & & 95 (57.3) & $40(36.7)$ & 1.0 \\
\hline Male & $28(46.7)$ & $43(40.6)$ & 0.445 & $71(42.7)$ & $69(63.3)$ & $2.30(1.4-3.79)$ \\
\hline \multicolumn{7}{|l|}{ Age } \\
\hline$<15$ years old & $45(75.0)$ & $70(66.0)$ & & $115(69.3)$ & $70(64.2)$ & 1.0 \\
\hline$\geq 15$ years & $15(25.0)$ & $36(34.0)$ & 0.163 & $51(30.7)$ & $39(35.8)$ & $1.25(0.7-2.1)$ \\
\hline \multicolumn{7}{|l|}{ Marital status } \\
\hline Single & 55 (91.7) & $87(82.0)$ & & $142(85.5)$ & $89(81.6)$ & 1.0 \\
\hline Married & $2(3.3)$ & $17(16.1)$ & & $37(11.5)$ & $17(15.6)$ & $0.73(0.37-1.44)$ \\
\hline Other (divorced, widow) & $3(5.0)$ & $2(1.9)$ & 0.039 & $5(3.0)$ & $3(2.8)$ & $0.96(0.18-4.74)$ \\
\hline \multicolumn{7}{|l|}{ Income per month ${ }^{b}$} \\
\hline US\$226.50 or more & $11(18.4)$ & $24(22.6)$ & & $35(21.1)$ & $16(14.7)$ & 1.0 \\
\hline US\$ 75.50-US\$ 226.50 & $26(43.3)$ & $52(49.1)$ & & $78(47.0)$ & $45(41.3)$ & $1.26(0.60-2.7)$ \\
\hline No income or US\$75.50 & $23(38.3)$ & $30(28.3)$ & 0.404 & $53(31.9)$ & $48(44.0)$ & $1.98(0.92-4.29)$ \\
\hline \multicolumn{7}{|l|}{ Schooling } \\
\hline None & $3(5.0)$ & 0 & & $3(1.8)$ & $2(1.8)$ & 1.0 \\
\hline High school or less & 20 (33.3) & $41(38.7)$ & & $61(36.7)$ & $42(38.5)$ & $1.03(0.13-9.3)$ \\
\hline Unknownc & $2(3.3)$ & $7(6.6)$ & & $9(5.4)$ & $6(5.5)$ & - \\
\hline Below school age ${ }^{c}$ & $35(58.4)$ & $58(54.7)$ & 0.092 & $93(56.1)$ & $59(54.2)$ & - \\
\hline \multicolumn{7}{|l|}{ Kind of dwelling } \\
\hline House or apartment & $43(71.7)$ & $74(69.8)$ & & $117(70.5)$ & $71(65.1)$ & 1.0 \\
\hline One-room house & $17(28.3)$ & $32(30.2)$ & 0.801 & $49(29.5)$ & $38(34.9)$ & $2.12(1.23-3.68)$ \\
\hline \multicolumn{7}{|l|}{ Animals in house } \\
\hline No & $14(23.3)$ & $32(30.2)$ & & $46(27.7)$ & $30(27.5)$ & 1.0 \\
\hline Yes & $46(76.7)$ & $74(69.8)$ & 0.637 & $120(72.3)$ & $79(72.5)$ & $1.01(0.57-1.80)$ \\
\hline \multicolumn{7}{|l|}{ Kind of urbanization } \\
\hline Urbanization in good condition & $21(35.0)$ & 30.2 & & $53(32.0)$ & $33(30.2)$ & 1.0 \\
\hline Urbanization in poor condition & $32(53.3)$ & $40(37.7)$ & & $72(43.3)$ & $39(35.8)$ & $0.87(0.47-1.63)$ \\
\hline Transitional or rural area & $7(11.7)$ & $34(32.1)$ & 0.012 & $41(24.7)$ & $37(34.0)$ & $1.45(0.74-2.83)$ \\
\hline
\end{tabular}


TABLE 3. Mean scores and standard deviation (SD) for three microenvironmental factors in cases and controls, metropolitan area of Belo Horizonte, Brazil, July 1999 to December 2000

\begin{tabular}{|c|c|c|c|c|c|}
\hline & $\begin{array}{l}\text { Hospital } \\
\text { controls } \\
\text { (No. = 60) } \\
\end{array}$ & $\begin{array}{c}\text { Neighborhood } \\
\text { controls } \\
(\text { No. = 106) } \\
\end{array}$ & & $\begin{array}{c}\text { Cases } \\
(\text { No. }=109) \\
\end{array}$ & \\
\hline Variable & Mean (SD) & Mean (SD) & $P$ value $^{\mathrm{a}}$ & Mean (SD) & $P$ value $^{\mathrm{b}}$ \\
\hline Indoor (range 7-17) & $9.21(1.89)$ & $9.46(1.78)$ & 0.40 & $9.82(2.1)$ & 0.05 \\
\hline Outdoor (range 12-41) & $26.9(6.57)$ & $28.03(6.75)$ & 0.26 & $30.07(6.98)$ & 0.003 \\
\hline Animal outdoor (range $10-50$ ) & $26.05(5.62)$ & $27.16(5.06)$ & 0.19 & $29.22(6.44)$ & $<0.001$ \\
\hline
\end{tabular}

TABLE 4. Odds ratios for visceral leishmaniasis associated with characteristics included in the final logistic regression models, metropolitan area of Belo Horizonte, Brazil, July 1999 to December 2000

\begin{tabular}{|c|c|c|c|c|c|c|c|c|c|}
\hline \multirow[b]{2}{*}{ Variables } & \multicolumn{3}{|c|}{$\begin{array}{l}\text { All cases and controls } \\
\quad(\text { No. }=275)\end{array}$} & \multicolumn{3}{|c|}{$\begin{array}{l}\text { Cases and neighborhood controls } \\
\qquad(\text { No. }=212)\end{array}$} & \multicolumn{3}{|c|}{$\begin{array}{l}\text { Cases and hospital controls } \\
(\text { No. }=120)\end{array}$} \\
\hline & Odds ratio & $95 \% \mathrm{Cl}$ & $P$ value & Odds ratio & $95 \% \mathrm{Cl}$ & $P$ value & Odds ratio & $95 \% \mathrm{Cl}$ & $P$ value \\
\hline \multicolumn{10}{|l|}{ Age $<15$ years } \\
\hline Male vs. female & 1.68 & $0.83-3.43$ & 0.147 & 1.73 & $0.82-3.60$ & 0.147 & 1.51 & $0.51-4.44$ & 0.447 \\
\hline \multicolumn{10}{|l|}{ Age $\geq 15$ years } \\
\hline Male vs. female & 7.02 & $2.20-22.20$ & $<0.05$ & 6.11 & $1.6-22.90$ & $<0.05$ & 7.42 & $1.13-48.42$ & $<0.05$ \\
\hline Indoor score ${ }^{\mathrm{a}}$ & 1.29 & $0.87-1.93$ & 0.202 & 1.62 & $0.98-2.70$ & 0.059 & 0.95 & $0.56-1.60$ & 0.863 \\
\hline Outdoor score ${ }^{a}$ & 1.49 & $1.03-2.14$ & 0.033 & 1.56 & $1.04-2.32$ & 0.029 & 1.34 & $0.78-2.29$ & 0.281 \\
\hline Animal outdoor score $\mathrm{a}^{\mathrm{a}}$ & 1.79 & $1.21-2.65$ & 0.003 & 1.66 & $1.08-2.55$ & 0.021 & 2.12 & $1.13-4.06$ & 0.019 \\
\hline Urbanization in poor condition ${ }^{b}$ & 0.53 & $0.16-1.72$ & 0.293 & $\mathrm{NC}^{\mathrm{c}}$ & $\mathrm{NC}^{\mathrm{c}}$ & 1.00 & 0.49 & $0.15-1.65$ & 0.253 \\
\hline Transitional or rural area ${ }^{b}$ & 1.19 & $0.29-4.82$ & 0.805 & $\mathrm{NC}^{\mathrm{c}}$ & $\mathrm{NC}^{\mathrm{c}}$ & 1.00 & 1.84 & $0.41-8.30$ & 0.425 \\
\hline
\end{tabular}

a For continuous variables, odds ratios refer to a difference of one standard deviation (SD). Indoor $S D=1.95$, Outdoor $S D=6.90$, Animal outdoor $S D=5.88$.

${ }^{b}$ Reference category = urbanization in good condition.

${ }^{c} \mathrm{NC}=$ Not calculated. Odds ratios were not interpretable because cases and controls were matched by neighborhood.

door, and animal outdoor scores were significantly higher in cases than in controls $(P<0.05)$ (Table 3$)$.

The results of logistic regression analyses are shown in Table 4 . Generally similar results were obtained for the full sample and each control group. The final models included age, sex, the interaction between age and sex, indoor score, outdoor score, animal outdoor score, and level of urbanization.

Male sex was positively associated with being a case, although associations were stronger in the older than in the younger age group. Outdoor score was consistently and positively associated with the odds of leishmaniasis in all models, although the association was not statistically significant for the hospital controls, possibly due to the small sample size. Animal outdoor score was positively and significantly associated with the odds of leishmaniasis in the full sample and in analyses using either set of controls. The odds of leishmaniasis were 1.79 times higher for each 5.88-point increase in score, after controlling for all other variables in the model. In hospital controls and in the full sample, living in a transitional or rural area was associated with a higher odds of leishmaniasis, but the estimates had wide confidence intervals that included the null value.

\section{DISCUSSION}

The dwellings that scored highest were houses that offered a better envi- ronment for the vector: a dirt yard, abundant organic material, shade, and humidity. Costa et al. (15) found that inadequate garbage collection and inadequate sewage disposal were associated with VL in Teresina, in the state of Piaui, Brazil. Although houses within a given area are likely to share these characteristics, variations from house to house may also play a role since how each of the persons maintains the microenvironment around their home varies. Some people change the microenvironment around their home completely, whereas others do not. Our results show that these features may be relevant to the occurrence of leishmaniasis.

Many entomological studies show that the vector, Lutzomyia longipalpis, 
has a broad-ranging feeding pattern that includes both domestic and wild animals (10). Although the presence of domestic animals inside the house was not significantly associated with leishmaniasis in our study, we found that animals in the neighborhood were associated with a greater odds of disease (Table 4). In Belo Horizonte, dogs are very common pets. In both case and control groups, the percentage of participants who kept pets was high, making the groups highly homogenous with regard to this variable. Our results do not point to the importance of any specific type of animal, but suggest that the frequency and variety of animals is a risk factor. In a large city like Belo Horizonte, the variety of animals is likely to be restricted, but it is worth noting that not only pigs, horses, and cows but also marsupials have been reported in the city.

Cases were more likely than controls to live in rural or transitional areas, although this difference was not statically significant. Adjusted odds ratios for the association between different levels of urbanization and leishmaniasis had wide confidence intervals. Because most of the controls were matched to cases by neighborhood, associations between level of urbanization and leishmaniasis could only be examined in cases and hospital controls, for which the sample size was small. This may have limited our ability to detect these associations. Future work needs to examine how different levels of urbanization are related to leishmaniasis.

We observed a significant interaction between sex and age, such that the association of male sex with leishma- niasis was stronger in persons aged 15 years and over than in those under 15. These results agree with prior work $(17,18)$ that also reported differences in the association of sex with leishmaniasis. Sharma et al. (17) observed a stronger association of male sex with leishmaniasis in persons over 15 than in those under 15 years of age. The authors hypothesized that adult women were protected against infection because of female hormones. In a study using rats, Satoskar et al. (19) showed that females were more resistant to infection than males. Females did not develop Lutzomyia mexicana lesions because they had a stronger Th1 response, which contributed to resistance to leishmaniasis (20).

Several limitations of our study should be considered. We believe that all cases were notified because the drugs for treatment are provided only after notification, but we cannot be certain that no cases were missed. Moreover, we analyzed only clinical cases. It is unlikely, however, that the inclusion criteria for cases resulted in substantial selection bias. Another limitation is that neither of the two methods for the selection of controls yielded a true population sample of noncases. Although the neighborhoodmatched controls approximated this population more closely than the hospital-matched controls, matching made it impossible to identify neighborhood factors with these data. Hospital controls were necessarily a selected sample that could have biased our estimates in unpredictable directions. It is reassuring, however, that the key associations we documented with the outdoor and neighborhood scores were found for both hospitaland neighborhood-matched controls.

Characteristics of the outdoor surroundings and the presence of animals in the local area were significantly associated with the odds of leishmaniasis in our sample. Although these microenvironmental factors need to be confirmed in other settings, they suggest important avenues for potential intervention. One important measure is to reduce the number of animals in the streets, including dogs, horses, and cows. These animals are frequent on Brazilian streets, and are the most common source of sandfly blood meals, according to entomological studies. Intervention and education programs should also focus on improving microenvironmental conditions by facilitating residents' ability to keep their gardens and yards free of the vegetation and soil conditions associated with leishmaniasis, and by reducing the number of animals such as pigs or chickens in urban areas. Preventing leishmaniasis in urban areas will likely require a set of measures that focus not only on individuals but also on the microenvironments of their homes and neighborhoods.

Acknowledgments. This work was supported by the Pan American Health Organization (PAHO Grant BRA/3176), the Fundação de Desenvolvimento da Pesquisa (FUNDEP, subproject 10/99), and the Coordenação de Aperfeiçoamento de Pessoal de Nível Superior (CAPES, BEX 3201/ 040). We thank the Center for Statistical Consultation and Research (University of Michigan) and Dr. Laura Klem for their help.

\section{REFERENCES}

1. United Nations Population Division. World urbanization prospects: the 2001 revision. Geneva: United Nations; 2002.

2. Sutherst RW. Global change and human vulnerability to vector-borne diseases. Clin Microbiol Rev. 2004;17:136-73.

3. Genaro O, Costa CA, Willians P, Silva JE, Rocha NM, Lima SL, et al. Ocorrência de calazar em área urbana da grande Belo Horizonte, MG. Rev Soc Brasil Med Trop. 1990: 23(2): 121 .

4. DATASUS. Available from: http://w3.datasus. gov.br/datasus/datasus.php. Accessed $1 \mathrm{Au}-$ gust 2006.

5. Oliveira CL, Assunção RM, Reis IA, Proietti FA. Spatial distribution of human and canine visceral leishmaniasis in Belo Horizonte, Minas Gerais State, Brazil, 1994-1997. Cad Saúde Publica. 2001;17(5):1231-39.

6. Evans T, Teixeira MJ, McAuliffe IT, Vasconcelos I, Vasconcelos AW, Sousa Ade A, et al. Epidemiology of visceral leishmaniasis in Northeast Brazil. J Infect Dis. 1992;166(5): 1124-32. 
7. Sherlock I. Ecological interactions of visceral leishmaniasis in the State of Bahia, Brazil. Mem Inst Oswaldo Cruz. 1996;91(6):671-83.

8. Cabrera MAA, Paula AA, Camacho LAB, Marzochi MC, Xavier SC, Silva AVM, et al. Canine visceral leishmaniasis in Barra de Guaratiba, Rio de Janeiro, Brazil: assessment of risk factors. Rev Inst Med Trop São Paulo. 2003;45(2):79-83.

9. Feliciangeli MD. Natural breeding places of phlebotomine sandflies. Med Vet Entomol. 2004;18(1):71-80.

10. Morrison AC, Ferro C, Tesh R. Host preferences of sand fly Lutzomyia longipalpis at an endemic focus of American visceral leishmaniasis in Colombia. Am J Trop Med Hygiene. 1993;49(1):68-75.

11. Alexander B, Carvalho RL, McCallum H, Pereira MH. Role of the domestic chicken (Gallus gallus) in the epidemiology of urban visceral leishmaniasis in Brazil. Emerg Infect Dis. [serial online] 2002; December [09/19/ 2005];8. Available from: http://www.cdc.
gov/ncidod/EID/vol8no12/01-0485.htm. Accessed 30 August 2005.

12. Hamilton JG, Mellor HE, Hamilton JG. Navigation of Lutzomyia longipalpis (Diptera: Psychodidae) under dusk or starlight conditions. Bull Entomol Res. 2003:93(4):315-22.

13. Barata RA, Silva JCF, Costa RT, Fortes-Dias CL, Silva JC, Paula EV, et al. Phlebotomine sand flies in Porteirinha, an area of American visceral leishmaniasis transmission in the State of Minas Gerais, Brazil. Mem Inst Oswaldo Cruz. 2004;99(5):481-7.

14. Souza CM, Pesssanha JE, Barata RA, Monteiro EM, Costa DC, Dias ES. Study on phlebotomine sand fly (Diptera: Psychodidae) fauna in Belo Horizonte, State of Minas Gerais, Brazil. Mem Inst Oswaldo Cruz. 2004;99(8):795-803.

15. Costa CHN, Werneck GL, Rodrigues JRL, Santos MV, Araujo IB, Moura LS, et al. Household structure and urban services: neglected targets in the control of visceral leishmaniasis. Ann Trop Med Parasitol. 2005;99(3):229-36.
16. Soares JF, Siqueira A. Introdução à estatística médica. First ed. Belo Horizonte: Universidade Federal de Minas Gerais; 2001.

17. Sharma MC, Gupta AK, Saran R, Sinha SP. The effect of age and sex on incidence of kalaazar. J Commun Dis. 1990;22(4):277-8.

18. Marty P, Le Fichoux Y, Pratlong F, GariToussaint M. Human visceral leishmaniasis in Alpes-Maritimes, France: epidemiological characteristics for the period 1985-1992. Trans Royal Soc Trop Med Hygiene. 1994;88:33-4.

19. Satoskar A, Al-Quassi HHK, Alexander J. Sexdetermined resistance against Leishmania mexicana is associated with preferential induction of a Th1-like response and IFN-g production by female but not male DBA/ 2 mice. Immunol Cell Biol. 1998;76:159-66.

20. Liew FY, O'Donnell CA. Immunology of leishmaniasis. Adv Parasitol.1993;32:161-259.

Manuscript received on 19 September 2005. Revised version accepted for publication on 11 September 2006.

RESUMEN Objetivos. Se investigaron los posibles factores microambientales de riesgo de leishmaniasis visceral en áreas urbanas y suburbanas y se elaboraron sistemas de puntuación del riesgo para caracterizar los hogares y los vecindarios. Estas puntuaciones

Estudio de casos y controles sobre factores microambientales de riesgo de leishmaniasis visceral urbana en una gran urbe de Brasil, 1999-2000

Palabras clave pueden ayudar a identificar dentro de las ciudades microambientes que implican un mayor riesgo de leishmaniasis visceral para sus habitantes.

Métodos. En este estudio de casos y controles, los casos fueron todas las personas con leishmaniasis visceral informadas entre julio de 1999 y diciembre de 2000 en el área metropolitana de Belo Horizonte, Brasil. Se utilizaron dos tipos de controles: de vecindario y de hospital. Los casos y controles se parearon por la edad ( \pm 2 años). Se establecieron cuatro puntuaciones para caracterizar el microambiente: interior de los hogares, exterior de los hogares, animales en los hogares y animales en el vecindario. También se consideró el nivel de urbanización del área.

Resultados. Se identificaron 106 controles de vecindario y 60 de hospital para los 109 casos. De estos, 69 (63,3\%) eran hombres y 40 (36,7\%) eran mujeres. La mayoría de los casos (64,2\%) tenían menos de 15 años de edad y 39 (35,8\%) tenían 15 años o más. La puntuación del exterior de los hogares (OR = 1,49; intervalo de confianza de $95 \%$ $[$ IC95\%] = 1,03-2,14) y de animales en el vecindario (OR = 1,79; $[1,21-2,65]$ ) mostraron una asociación significativa con la posibilidad de padecer leishmaniasis visceral en la muestra. También se encontró una interacción significativa entre el sexo y la edad. Los hombres de 15 años de edad o más tuvieron mayor probabilidad de padecer leishmaniasis visceral que las mujeres de 15 años o más (OR =7,02; [2,20-22,20]).

Conclusiones. La presencia de animales en el vecindario estuvo asociada con una mayor posibilidad de leishmaniasis visceral. Los casos presentaron mayor probabilidad de vivir en áreas rurales o de transición que los controles, aunque esta diferencia no fue estadísticamente significativa, posiblemente debido al pequeño tamaño de la muestra.

Estudios de casos y controles, leishmaniasis visceral, factores de riesgo, urbanización, Brasil. 